\title{
Reform and Application of Using Blended Learning in Teaching and Learning Systematic Anatomy
}

\author{
Jian-Guo ZHANG \\ Department of Anatomy, Huzhou University, Huzhou, Zhejiang, P.R. China \\ zjgyc@163.com
}

Keywords: Blended learning, Anatomy, Classroom teaching, Online learning.

\begin{abstract}
With the development of Internet, digital technology, anatomy teaching faces a new problem. In order to adapt to the development of medical education and the transformation of medical model, strengthen the cultivation of undergraduate students learning ability of human anatomy, we conducted a "blended learning mode ".The reform and application shows that this method can enhance students' interest in learning human anatomy, improve the ability of autonomous learning.
\end{abstract}

\section{Introduction}

Blended learning comes from the last century 90s American enterprise training. With the development of the Internet, digital technology, the teachers' leading role of the traditional ways of learning and network learning of students' learning initiative, form a new mode of blended learning [1 2]. This teaching mode makes teacher's dominant and the students' initiative of complementary advantages, to achieve the best learning effect. X.M. Zhang, W. T. and H. Chen further studied the relation of blended learning and network learning [3-4]. In the medical profession anatomy teaching, the A.P. Wang, D.F. Jiang, J.H.X ia et al explore the relationship between human anatomy and network learning [5]. We according to the development of modern education technology and characteristics of classroom teaching, online learning, human anatomy specimens observation, to explore blended learning in anatomy teaching reform and practice. This reform will it cultivates the good character persons talented in medical science and made some beneficial exploration.

\section{The Ideas and Methods of Curriculum Reform}

\section{Blended Learning Mode of Education}

Human anatomy can be taught by teachers teaching methods, students in the completion of human anatomy study, have been proved. But on the other hand, if the student learning, the teacher guidance, students can learn human anatomy? Intuitively, I think it is difficult to success. In view of the theory of education, however, these two views, all is possible!

Objectivist epistemology thought the world is real, structure, and this structure can be recognized. Therefore, the objective is "teacher-centered" epistemological basis of teaching methods, knowledge can be passed through the teachers' teaching to students. In the process of teaching, the teacher convey knowledge to students, teachers in a leading position in the process of teaching.

Constructivism believes that knowledge is learners to interact with the environment, through personal experience in independent construction, knowledge learned by students themselves. As a result, students in the learning process, in a central position. This kind of epistemology is the basis of "student-centered" teaching mode, denied knowledge can be taught, denies the leading role in the process of teachers in the teaching.

From education point of view, objectivism and constructivism teaching methods in opposition of the two extremes. Objectivism of the teaching method marked by the lecturer. Constructivist teaching methods of the former marked by self-study. But in the actual teaching and constructivism teaching each link, to implement, cannot leave the center of the teachers and guidance role. Therefore, teachers' leading role and students' main body effect are closely linked to complete the 
teaching work. Mix the two recognition methods together, is the epistemological basis of blended learning mode. As a result, the students' autonomous learning teaching methods and teachers as the guide, mainly teaching methods, to conduct anatomy teaching, cultivating students' knowledge skills and ability to innovate, to further improve the quality of teaching, there are theoretical basis of education.

\section{The Teaching Object}

Choose our school level 2012 to level 2013 clinical medicine professional clinical medicine specialty students, each grade of 90 , grade 2012 students class is over, can be used as a traditional teaching group. Grade 2013 teaching method, adopt the hybrid as experimental group, a total of 90 students. Students to take part in the unified national college entrance examination, the selection of enrolled students, aged between 18 to 19. Students work in groups of 2 or 3, before class, teachers will be teaching outline and the target of classroom teaching to students, and provide some learning resources, for students to familiar with the course content and the subject. Teachers to refine the teaching material content, on the basis of the multimedia courseware, theory explanation. In the experiment, further observe the human body structure, students review and thinking. In the seminar, the student statement, this paper introduces the relationship between the anatomical structure and related disease, and learns to write summary.

\section{Open Form of Experimental Teaching}

Lab is open to students is the basic condition of students' autonomous learning. We strengthened the construction of practical teaching environment, configuration of four anatomy laboratory, 1 specimen showroom. Each lab can accommodate about 20 of them. Each lab is equipped with two human specimens, one skeleton. Each human specimens according to the human body system configuration small specimens, and equipped with model as a supplement. Also comes with a number of anatomy teaching film, video and CD. Samples in the showroom, there are more than 800 specimens.

Experiment teaching of autonomous learning idea is: to guide students to understand the structure of human body each organ and adjacent to the relationship. Experiment course content design, write "human anatomy practice guidance", "human anatomy homework, inspire students to think about the relationship between structure and other structures adjacent to the. Students read, thinking, application and extension knowledge for students. The content of the student internship report with drawing. Student internship report increased clinical thinking and conduct clinical case discussion section, make curriculum content theory with practice more closely.

\section{Anatomical Network Course Construction and Online Learning}

Human anatomy network course by human anatomy course, anatomical video database and teaching resources, etc. Teachers can carry out online teaching. Students can register on the Internet, online learning, and course content; submit online learning activities such as homework.

Online teaching guiding ideology and way of thinking: 1, to the human body anatomy teaching content, to clear the teaching goal and requirements. Specific content clear and concise; 2, provides the corresponding knowledge of image, animation, links, images with text and hot tips. 3, the network related resources, including resource websites related to human anatomy, subject research progress and so on, provide access to knowledge, as a student to study the supplement and extension.

Online discussion, answer: teachers and students, between students and students, can carry out online two-way discussion. Students ask the teacher, the teacher answer, students can also request the teacher to answer. This way of communication provides a good environment for students and teachers.

Online job: teacher according to the teaching content, to the topic of students thinking. Students can choose according to their own knowledge, ability to answer.

Online self-test: in accordance with the requirements of teaching outline, follow the principle of combination of effectiveness and scientific nature, the design of learning content review questions. 
Test design emphasizes students usually study and students' ability to obtain knowledge and the comprehensive analysis of assessment. Each test topic quantity is 100, divided into different types, mainly composed of multiple choices, computer gives the correct answer and score. Students can timely know the degree of their own learning and mastering knowledge; timely adjust the personal learning progress.

\section{Blended Learning Mode of Different Ways}

\section{Different Teaching Methods, Strengthen the Diversity of Learning Ability}

The reform of the theory class teaching method. Now theory, most is to use of multimedia electronic lesson plans, this to improve the teaching time, is very meaningful. The traditional blackboard writing, brief teaching method began to decline. Teaching process show that the anatomy of courseware computer multimedia technology, image real, rich, is helpful for students to the understanding of the morphological structure. But traditional diagram of blackboard writing, teaching method, is advantageous to the student's understanding of morphological structure. Our teaching method is now theory based on courseware is given priority to, complementary with landscape of hybrid method teaching.

At the same time, to carry out the relationship of anatomical structures and disease case discussion. Each study group to find out an example, to illustrate the close relationship of anatomical structures and disease. In learning, discussion will refer to literature and thinking, for the report.

For example, the students discussed the: " Hepatic portal venous hypertension and Venous traffic team", and will study summary, in the form of a message, on the course website. Students learn by teaching mixed with different teaching methods, is helpful to students' personalized learning ability development.

\section{The Mixture of Online Learning and Specimen Experiment, Highlight the Cultivation of Autonomous Learning Ability}

Experimental teaching is an important part of the body morphology teaching, the experiment is not the repeat of theory class teaching. It is the extension and expansion of knowledge and ability training process. In the experimental teaching, on the one hand, through electronic teaching demonstration, teachers' demonstration, and structure identification; Students watch the physical specimen, on the other hand, according to their own learning needs, purposeful use of specimens and other teaching resources, to strengthen the students' knowledge of anatomy, effectively complete theoretical knowledge and specimen.

We will be a lot of specimens picture fills in homemade website, selectively choose well-known experts and scholars of anatomy at the university of domestic well-known key video data, for teachers and students to provide scientific and boutique learning materials. In order to encourage students to actively participate in autonomous learning activities, we will be online learning human anatomy knowledge self-test result as part of the grades. Anatomy of the online tutorials, pictures, self-test, etc, improve the students' study enthusiasm and the accuracy of knowledge, cultivate the students' ability of autonomous learning.

\section{The Mixture of Classroom Teaching and Specimen Autopsy on the Corpses, Highlight the Cultivation of Comprehensive Quality}

According to the process of teaching, for students to provide other convenient, such as lead the students to visit the laboratory, salvage took part in the body and the perfusion of latex, deepen students' understanding and the understanding of human anatomy each link and processing.

In the experimental teachers' guide and organization, encourage students to participate in some simple specimen production activities. The students use old, used experimental specimens, making the specimens and are suitable for the system with practical value anatomical specimens of experimental teaching. Students through the experiments, further exploration of anatomical 
knowledge, and consolidate knowledge, to enhance the students' interest in learning. More major is set up for students start work platform, let the students not only learn the knowledge in the operation, and to exercise the ability of students to make a specimen in person, at the same time, also needed to complement and perfect the laboratory teaching, to save the source of resin, reduce the experimental expenditure.

\section{Evaluation of Curriculum Reform}

\section{The Final Exam}

The examination paper proposition, pay attention to for students to master knowledge, pay attention to the knowledge, ability cultivation, way of thinking of the inspection. Experimental test scores were $81.86 \pm 9.14 \mathrm{~mm}$, without fail students, the control test scores are: $74.48 \pm 9.24$, there are two students failed the exam, compare performance scores $(\mathrm{P}<0.05)$.

\section{The Student Questionnaire Investigation of Teaching Reform}

The student questionnaire. To student's questionnaire survey showed that $97 \%$ of the students think that this teaching reform is reasonable; $96 \%$ of the students think that improve the ability of autonomous learning, learning harvest a lot; $96 \%$ of the students think could improve the ability of thinking to understand, improve the comprehensive induction ability; $96 \%$ of the students think that contact the actual classroom teaching, to broaden the knowledge.

\section{Students to the Teacher Evaluation Questionnaire}

Students think that teachers in the teaching of this course theory content is clear, concept of accurate, coherent, can stimulate their interest in learning. In the experiment teaching, the teacher is responsible earnestly, causes the student to fully understand the related theory knowledge, and be able to use knowledge, to complete the experiment contents stipulated in the syllabus. Network curriculum content is rich, is good for students' self-study. Students in this course teachers' teaching assessment scores for "good".

\section{Conclusion}

Anatomy course we used the hybrid learning model, design model, the teacher through teaching, guide students to use network resources to learn, through inquiry learning, students completed the course teaching, and achieved good teaching effect, initially formed "anatomy of the blended learning model". This kind of learning pattern, already play a guide to the leading role of teachers, and give full play to the students' initiative, enthusiasm and creativity, complementary advantages in many aspects, causes the student to obtain the best learning effect.

The problem: the teacher enthusiasm high, but a few students autonomous learning enthusiasm lower than we expected. The minority students' participation is not enough, individual students are reluctant to spend too much time and energy; On the other hand, a few students don't adapt to this kind of active learning pattern, is still used to the classroom teaching mode.

\section{Reference}

[1] X. M. Zhuang, H. Chen. Blended Learning, A New Teaching Mode, J. Journal of Shenyang Agricultural University(Social Sciences Edition). 11(2) (2009) 212-215.

[2] S. J. Chen , Analysis on the Characteristic of Mixed Learning, J. Journal of Qujing Normal University. 25 (2006) 94-98.

[3] X. M. Zhang , W. T. He, Research on Network Teaching System Model Based on the Flipped Classroom, J. Modern Educational Technology. (2013) 21-25. 
[4] H. Chen, Mistaken Ideas in Adult Network Learnings External Monitoring and Basic Solutions, Journal of Beijing Institute of Education , J. 23 (2009) 68-70

[5] A. P. Wang, D. F. Jiang, J. H Xia et al, The Research and Development of Network Teaching Platform on Anatomy and Physiology, J. Journal of Shangrao Normal University 29( 2009) 69-74. 